\title{
Factors influencing intention to continue employment in Japanese hospital nurses working at tertiary emergency medical facilities
}

\author{
Kanako Honda ${ }^{* 1}$, Emiko Takamizawa ${ }^{2}$ \\ ${ }^{1}$ Shiga University of Medical Science, Shiga, Japan \\ ${ }^{2}$ Department of Nursing, Kansai University of International Studies, Hyogo, Japan
}

Received: May 12, 2017

DOI: $10.5430 /$ jnep.v7n11p44

\author{
Accepted: June 1, 2017 \\ Online Published: June 20, 2017 \\ URL: https://doi.org/10.5430/jnep.v7n11p44
}

\begin{abstract}
Objective: The study purpose was to investigate influencing factors related to nurses' intention to continue employment in tertiary emergency medical facilities.

Methods: A self-report questionnaire survey was conducted, and responses were collected by mail. We investigated seven factors associated with the intention to remain employed that were determined by preliminary research. Data were analyzed using a covariance structure analysis.

Results: Of the 561 responses received, 461 were found to be valid for analysis. A model showing relationships among the five factors (organizational commitment, job stress, job satisfaction, nurse-physician collaboration, and intention to remain employed) was created. Organizational commitment and job stress were directly related to intention to continue employment, while, nurse-physician collaboration demonstrated effects on the entire model.

Conclusions: The strongest factor observed was organizational commitment. The types of institutions examined in the present study almost exclusively treat seriously ill patients. This may explain why nurse-physician collaboration affected the entire model. In a tertiary emergency facility, a nurse can more easily play a critical role in the healthcare process. In the future, it will be important to consider these factors when creating an organizational climate conducive to continued employment.
\end{abstract}

Key Words: Intention to continue employment, Tertiary emergency medical facilities, Emergency nursing, Influencing factors

\section{INTRODUCTION}

The Japanese emergency care system is characterized by three levels of care. Primary emergency care treats slightly injured patients who do not need hospitalization. Secondary emergency care treats patients who need hospitalization, but are not in a critical condition. Tertiary emergency care treats seriously ill patients in life-threatening emergencies, such as ischemic heart disease, serious trauma, and cerebrovascular disorders. Nurses experience fatigue due to the exceptionally heavy labor involved in saving lives. Additionally, nurses' mental strain can be serious enough to require extensive treatment. Further, along with the original roles of a nurse, they must perform many support roles for the treating physician. These issues can cause nurses to leave the workplace. However, there is insufficient research on nurses who work in the tertiary care hospital setting.

In general, various problems can occur when many nurses resign from a hospital. For example, education costs can in-

\footnotetext{
${ }^{*}$ Correspondence: Kanako Honda; Email: iy7k@belle.shiga-med.ac.jp; Address: Shiga University of Medical Science, Seta Tsukinowa-cho, Otsu, Shiga, Japan.
} 
crease when inexperienced nurses are employed in great numbers. Elsewhere, a shortage of experienced nurses has a negative influence on patient satisfaction with nursing care. ${ }^{[1-3]}$ Nurse retention and related development of nursing skills are essential for providing patients with high quality, stable nursing care.

In Japan, research has focused on job satisfaction as a factor of nurse retention in the hospital setting. However, research abroad has examined other factors such as management style, group cohesion, organizational commitment, job stress, and nurse-physician collaboration and relations, in addition to job satisfaction. ${ }^{[4-7]}$ These studies have revealed a variety of factors associated with the job satisfaction of nurses settling into the workplace.

Against this background, we investigated various factors influencing nurses' intention to remain engaged in Japanese emergency care.

\subsection{Purpose}

The study purpose was to investigate factors influencing intention to continue employment in Japanese hospital nurses working at tertiary emergency medical facilities.

\subsection{Theoretical model}

The current theoretical model is based on the work of Tourangeau and Cranley, ${ }^{[7]}$ who described various predictor variables related to the intention of nurses working in acute care hospitals to remain employed until retirement. The in- dependent variables of this model included job satisfaction, organizational commitment, nurse group cohesion, and personal characteristics of nurses (e.g., age, years of nursing experience, gender, educational preparation, number of years in the current post/workplace). However, this model only explained $34 \%$ of the variance in nurses' intention to continue employment at a specific institution. Therefore, in the current study, we added the information provided by a meta-analysis of job satisfaction conducted by Zangaro et al. ${ }^{[8]}$ According to their results, we also examined work stress, collaborative relationships, and autonomy of nurses and physicians. Taking all of the aforementioned information into account, we hypothesized that job satisfaction would precede organizational commitment, ${ }^{[9]}$ that job satisfaction would be a buffering factor against job stress, ${ }^{[9]}$ that nurse-physician collaboration would be associated with organizational commitment, ${ }^{[10]}$ and that job stress would be directly associated with intention to continue employment. ${ }^{[11]}$ A flow chart of the theoretical model used in the current study is presented in Figure 1.

\subsection{Ethical considerations}

The study was approved by the Institutional Review Boards of Osaka Prefecture University. Participants were informed of the purpose and methods of the study, as well as the risks/benefits of participation, confidentiality of their data, and voluntary nature of participation. Return of the anonymous questionnaire was considered as the provision of informed consent.

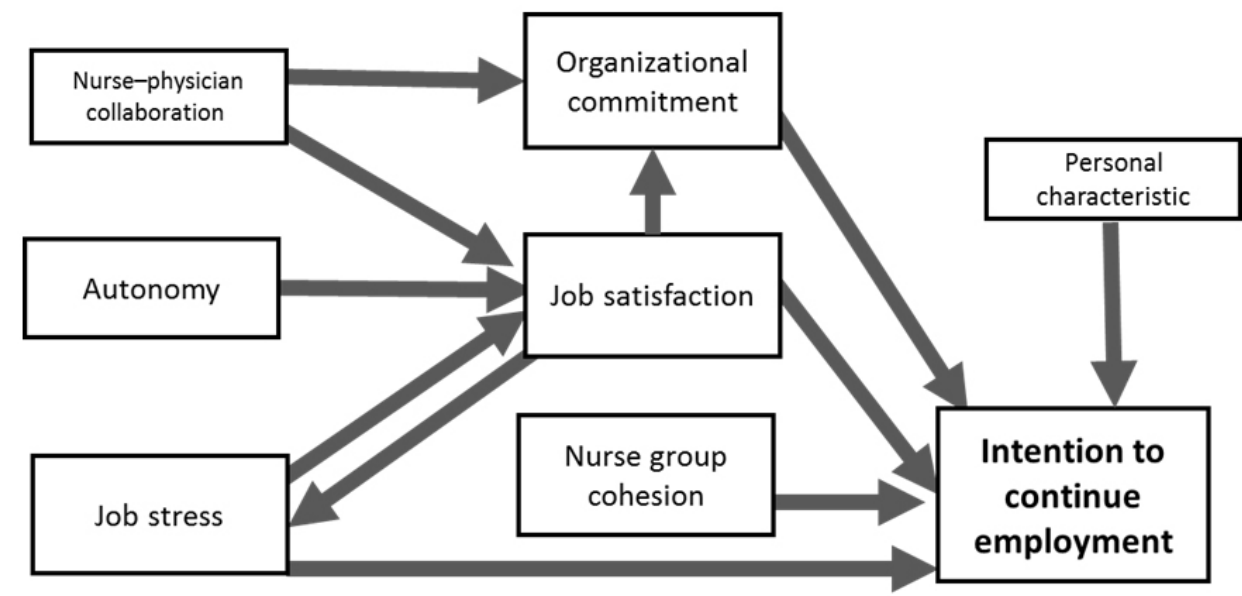

Figure 1. Theoretical model

\section{MethodS}

\subsection{Study design}

This cross-sectional descriptive study was conducted from December, 2009 to March, 2010.

Published by Sciedu Press

\subsection{Participants and procedures}

An invitation to participate was presented to 160 randomly sampled nurse directors of tertiary emergency facilities throughout Japan, of which, 32 provided permission to conduct the study in their organization. Therefore, the sample for 
this study consisted of 1,318 registered nurses (from novice to expert), employed on a full-time basis at these 32 tertiary emergency facilities. An anonymous, self-report questionnaire survey was conducted, and responses were collected by mail. Seven specific factors, determined to be pertinent to nurse turnover through preliminary research, were examined. Additionally, the following personal attributes of nurses were investigated: age, sex, educational history, years of nursing experience, years of service at the current facility, and years of tertiary emergency nursing experience. Data were analyzed by a covariance structure analysis.

\subsection{Measures}

\subsubsection{Intention to continue employment}

Intention to remain employed is the intention of a nurse to continue to work at the current workplace. This was measured on a 3-point scale ranging from 1 (do not intend to continue working) to 3 (intend to continue working).

\subsubsection{Job satisfaction}

Job satisfaction was defined as the degree of positive affective orientation that nurses hold towards their employment. This was measured by the Japanese version of the McCloskey/Mueller Satisfaction Scale (MMSS), created by Shijiki. ${ }^{[12]}$ This scale comprises 31 items, and it was developed from the viewpoint of three types of rewards, specifically pertaining to security, social, and psychological dimensions. Responses to items are made on a five-point Likert scale ranging from 1 (very dissatisfied) to 5 (very satisfied). The Cronbach's $\alpha$ for the J-MMSs was 0.90 in a previous study.

\subsubsection{Nurse group cohesion}

"Nurse group cohesion" is defined as the degree of attraction that nurses felt towards their work group and their motivation to be a member of that group. ${ }^{[7]}$ This was measured using a tool developed by our research group. It integrates the eight-item Group Cohesiveness Scale, created by Nishibori et al., ${ }^{[13]}$ with the one-item Nurses' Group Cohesiveness Scale, created by Tourangeau and Cranley. ${ }^{[7]}$ Responses to the items are made on a four-point Likert scale ranging from 1 (weak group cohesion) to 4 (strong group cohesion). The Cronbach's $\alpha$ for this scale was reported to be 0.85 .

\subsubsection{Job stress}

Job stress is related to both a nurse's work and the working environment. Specifically, this relates to workload that an individual perceives as being difficult to handle. ${ }^{[14,15]}$ This was measured by the Occupational Stress Recognition Scale created by Yamase et al., which contains 32 items. This scale was developed for nurses working in the tertiary critical care centers in Japan. Therefore, this scale contains items that are typical issues encountered while working at a tertiary emergency facility. The items include issues related to "emergency care", "handling microelectronic equipment", and "critical judgment". Responses to items are made on a six-point Likert scale ranging from 1 (low stress) to 6 (high stress). The Cronbach's $\alpha$ for this scale was reported to be 0.92 .

\subsubsection{Autonomy}

Professional autonomy is based on personal ethics, morality, and self-control, and it pertains to behavior that is not controlled by others or dependent on authority. ${ }^{[16]}$ To assess levels of autonomy, we used the Japanese version of the 30item Dempster Practice Behaviors Scale (DPBS), created by Koyano. Responses to items are made on a five-point Likert scale ranging from 1 (low autonomy) to 5 (high autonomy). The Cronbach's $\alpha$ for this scale was reported to be 0.84 .

\subsubsection{Nurse-physician collaboration}

Nurse-physician collaboration is a relationship in which a nurse and physician consider each other to be part of a team, and, as such, participate together in the planning and decision making towards a common goal. This relationship was measured via a tool developed by our research group based on the findings of a preliminary study conducted in a tertiary care facility (97 items). ${ }^{[17]}$ Responses to items are made on a five-point Likert scale ranging from 1 (low collaboration) to 5 (high collaboration). The Cronbach's $\alpha$ for this scale was reported to be 0.98 .

\subsubsection{Organizational commitment}

Organizational commitment is defined as the degree of attachment that nurses have towards their organization. ${ }^{[7]}$ Based on the previous work by Allen and information provided by the Organizational Commitment Scale developed by Meyer et al., we utilized three dimensions of the Japanese edition of the Organizational Commitment Scale, created by Takahashi et al. (18 items). Three dimensions included in this scale are "affective commitment", "normative commitment" and "continuous organizational commitment". Responses to items are made on a seven-point Likert scale ranging from 1 (low commitment) to 7 (high commitment). The Cronbach's $\alpha$ for this scale was reported to be 0.90 .

\subsection{Data analysis}

Analyses included descriptive statistics and a covariance structure analysis. A one-way ANOVA was performed on gender and educational background. The covariance structure analysis permitted a description of the relative influence of each variable on intention to continue employment in tertiary emergency medical facilities, allowing for the development of an explanatory model. SPSS 18 for Windows (SPSS Inc, Chicago, IL, USA) and Amos 19 were used, and 
significance was set at $5 \%$ for all analyses.

\section{Results}

A model showing relationships among the five factors was obtained from the results of the covariance structure analysis. Job stress and organizational commitment were directly related to intention to continue employment. A total of 561 responses were received (rate of collection $=42.6 \%$ ). However, only 251 of them (44\%) did not display any missing values, and were therefore found to be valid for analysis. Table 1 shows the characteristics of the study subjects. Females represented $91.6 \%$ of respondents, which is not surprising, as nursing is a female-dominated profession in Japan. The mean age was 34.2 years $(\mathrm{SD}=7.55$ years; range $=21-59$ years $)$, and the mean years of nursing experience was 12.1 years ( $\mathrm{SD}=7.33$ years; range $=1-35$ years $)$. Further, mean years of experience working in the present hospital was 10.0 years $(\mathrm{SD}=7.14$ years; range $=1-33$ years $)$, and mean years of experience working in tertiary emergency medical facilities was 4.81 years ( $\mathrm{SD}=3.99$ years; range $1-32$ years). Concerning education level, $52.8 \%$ were diploma graduates and $46.2 \%$ had graduated from a nursing baccalaureate program.

A one-way ANOVA was performed to analyze differences in intention to continue employment based on gender and educational background. However, these variables failed to show a significant association with the intention to continue employment.

The means, standard deviations, and range of scores for each variable included in the model, aggregated to the unit level, have been shown in Table 2. Table 3 shows the Cronbach's $\alpha$ coefficient for the seven variables and intention to continue employment. Reliability was confirmed, with internal consistency coefficients ranging from 0.83-0.98. Subsequently, the correlation among the factors was examined. Years of nursing experience and years at the current hospital were excluded from the analyses that followed, as they exhibited strong correlations $(r=0.87-0.95, p<.01)$ with age, years of nursing experience, and years of experience at the current hospital (see Table 4).

Table 1. Demographic variables for subjects $(n=251)$

\begin{tabular}{lll}
\hline Variables & & $\mathbf{n} /$ mean (SD/\%) \\
\hline \multirow{2}{*}{ Gender } & Male & $21(8.36 \%)$ \\
Age & Female & $230(91.63 \%)$ \\
& & $34.2(\mathrm{SD} \pm 7.55)$ \\
Educational & Diploma & $183(72.90 \%)$ \\
background & Associate degree & $25(9.96 \%)$ \\
in nursing & Bachelor's degree & $39(15.54 \%)$ \\
& Master's degree & $6(2.39 \%)$ \\
Years of nursing experience & $12.10(\mathrm{SD} \pm 7.33)$ \\
Years of emergency care experience & $4.81(\mathrm{SD} \pm 3.99)$ \\
\hline
\end{tabular}

Table 2. Mean, standard deviation of each factor $(\mathrm{N}=251)$

\begin{tabular}{|c|c|c|c|c|}
\hline Variables & Minimum & Maximum & Mean & SD \\
\hline Intention to remain employed & 1 & 3 & 2.1 & 0.7 \\
\hline Age & 22 & 59 & 34.2 & 7.6 \\
\hline Years of nursing experience & 1 & 33 & 12.1 & 7.3 \\
\hline Years working in current hospital & 1 & 32 & 10.0 & 7.1 \\
\hline Years of emergency care experience & 1 & 32 & 4.8 & 4.0 \\
\hline Organizational commitment & 26 & 116 & 71.1 & 12.9 \\
\hline Nurse group cohesion & 12 & 36 & 24.2 & 4.4 \\
\hline Job satisfaction & 41 & 125 & 86.0 & 14.2 \\
\hline Autonomy & 49 & 128 & 85.9 & 13.6 \\
\hline Job stress & 61 & 192 & 118.5 & 18.9 \\
\hline Nurse-physician collaboration & 154 & 485 & 299.9 & 47.7 \\
\hline
\end{tabular}

Table 3. The Cronbach's $\alpha$ of each measure $(\mathrm{N}=251)$

\begin{tabular}{lll}
\hline Factor & number of the items & Cronbach's $\boldsymbol{\alpha}$ \\
\hline Organizational commitment & 18 & 0.83 \\
Nurse group cohesion & 9 & 0.85 \\
Autonomy & 30 & 0.91 \\
Job satisfaction & 31 & 0.91 \\
Job stress & 32 & 0.92 \\
Nurse-physician collaboration & 97 & 0.98 \\
\hline
\end{tabular}

Published by Sciedu Press

\subsection{Overall model result}

We performed an exploratory covariance structural analysis. Significant associations were adopted at the $5 \%$ level of significance. The model was developed using seven factors (see Figure 2). The model displayed an acceptable fit: GFI $=.995, \mathrm{AGFI}=0.980, \mathrm{CFI}=1.000$, and RMSEA $=.0000$. The following variables had direct effects on the intention to continue employment: organizational commitment $(\beta=$ $.39)$ and job stress $(\beta=-.18)$. Nurse-physician collaboration 
and job satisfaction exhibited indirect effects. The $R^{2}$ for intention to continue employment was 0.20 .

Nurse-physician collaboration had a direct effect on organi- zational commitment $(\beta=0.19)$, as well as an indirect effect via job satisfaction $(\beta=0.42)$. Job satisfaction had a direct effect on organizational commitment $(\beta=0.214)$ and on job stress $(\beta=-0.14)$.

Table 4. Correlation matrix of the factors

\begin{tabular}{|c|c|c|c|c|c|c|c|c|c|c|c|}
\hline Factor & 1 & 2 & 3 & 4 & 5 & 6 & 7 & 8 & 9 & 10 & 11 \\
\hline 1. Intention to remain employed & 1.0 & & & & & & & & & & \\
\hline 2. Age & $.18^{* *}$ & 1.0 & & & & & & & & & \\
\hline 3. Years of nursing experience & $.16^{* *}$ & $.95^{* *}$ & 1.0 & & & & & & & & \\
\hline 4. Years worked at current hospital & $.15^{*}$ & $.82^{* *}$ & $.87^{* *}$ & 1.0 & & & & & & & \\
\hline 5. Years of emergency care experience & $.20^{* *}$ & $.37^{* *}$ & $.36^{* *}$ & $.45^{* *}$ & 1.0 & & & & & & \\
\hline 6. Organizational commitment & $.42^{* *}$ & $.33^{* *}$ & $.33^{* *}$ & $.34^{* *}$ & $.16^{* *}$ & 1.0 & & & & & \\
\hline 7. Nurse group cohesion & $.40^{* *}$ & .12 & .12 & $.16^{* *}$ & $.15^{* *}$ & $.59^{* *}$ & 1.0 & & & & \\
\hline 8. Job satisfaction & $.22^{* *}$ & $.32^{* *}$ & $.30^{* *}$ & $.27^{* *}$ & $.30^{* *}$ & $.38^{* *}$ & $.45^{* *}$ & 1.0 & & & \\
\hline 9. Autonomy & $.18^{* *}$ & -.08 & -.06 & -.02 & .05 & $.29^{* *}$ & $.41^{* *}$ & $.27^{* *}$ & 1.0 & & \\
\hline 10. Job stress &.$-26^{* *}$ & $-.13^{*}$ & -.01 & -.01 & $-.18^{* *}$ & $-.21^{* *}$ & $-.31^{* *}$ & $-.40^{* *}$ & $-.39^{* *}$ & 1.0 & \\
\hline 11. Nurse-physician collaboration & $.14^{*}$ & .02 & .03 & .03 & .08 & $.28^{* *}$ & $.42^{* *}$ & $.29^{* *}$ & $.42^{* *}$ & $-.21^{* *}$ & 1.0 \\
\hline
\end{tabular}

$* p \leq .05,{ }^{* *} p \leq .01$

3.2 Factors influencing nurses' intention to continue employment

"Organizational commitment" had the greatest impact on nurses' intention to continue employment in tertiary emer- gency medical facilities in this model. In addition, the factor of "nurse-physician collaboration" influenced the model overall. Job satisfaction was a buffering factor for work stress and it indirectly influenced intention to continue employment.

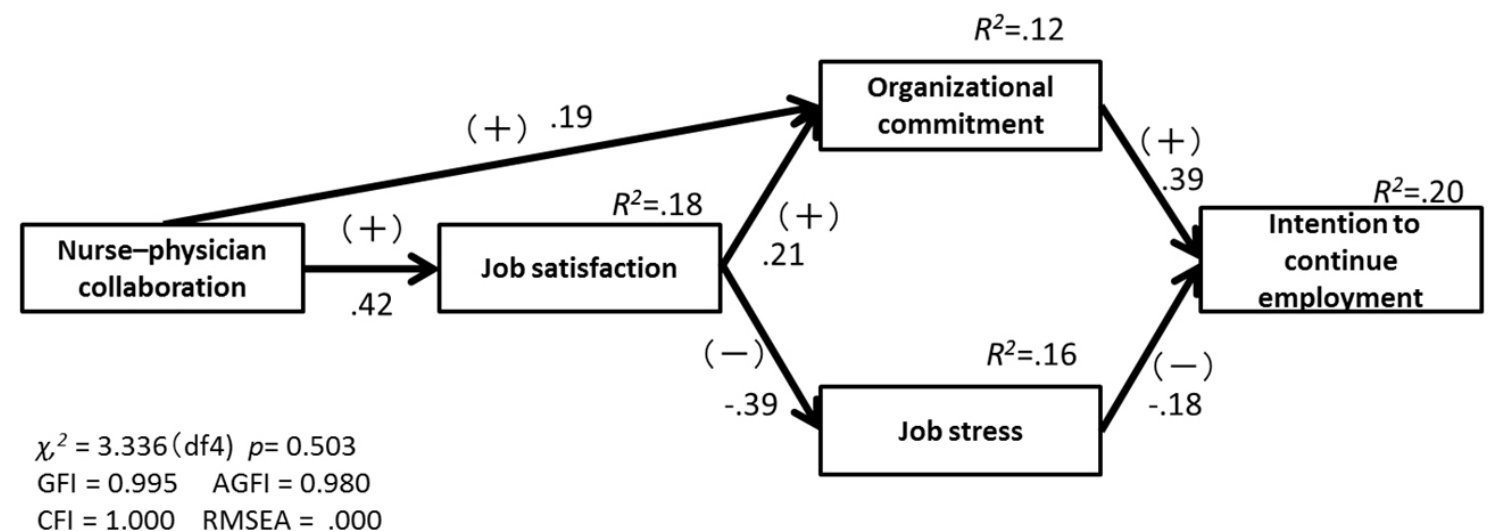

Figure 2. Model of intention to continue employment in Japanese hospital nurses working at tertiary emergency medical facilities

\section{Discussion}

\subsection{The characteristics of the model regarding intention to continue employment and factors influencing the same}

Organizational commitment was the strongest factor affecting the intention to continue employment. A number of studies confirm the importance of organizational commitment in influencing the intention to leave. ${ }^{[9,18]}$ Thus, the present findings support those of the present study these preceding studies. Currently, it is thought that a systematic commitment consists of the three components of affective commitment, normative commitment, and continuance commitment. Affective commitment indicates that a strong emotional attachment to the organization results in a high probability that employees will not resign from the organization. Nanba et al. ${ }^{[18]}$ suggested that the affective and normative components of an organization were significant predictors of intention 
to leave the organization among 524 registered nurses in Japan. Therefore, it is necessary to support the idea that nurses should actively participate within the working environment, develop a sense of responsibility pertaining to the success of the institution, and acquire an attachment toward the organization. Many previous studies have indicated that job satisfaction influences intention to continue employment, but the current findings revealed job satisfaction as a preceding factor to organization commitment and job stress, and it influenced the intention to continue employment indirectly. Nurses working in tertiary emergency facilities often treat serious cases, and high stress and excessively heavy labor are common job features. Therefore, it is a necessity for nurses working in tertiary emergency facilities to want to belong to this workplace, to consider it their inherent responsibility to work, and to derive satisfaction from working in such an environment.

Additionally, nurse-physician collaboration displayed an influence on the entire model of intention to continue employment. As the type of institution included in the present study almost exclusively treat seriously ill patients, this finding may be a unique characteristic of the model developed.

Job stress was shown as a negative determinant of the intention to continue employment in the present study. As such, it is necessary to reduce the stressors that are characteristic of these types of facilities, to promote retention. In preceding research, job stress was often revealed as a precedent factor of job satisfaction. However, in the current study, job satisfaction was reported to be a precedent factor of job stress.

Shimazu ${ }^{[19]}$ reported that an increase in job satisfaction weakened reactions to stress. Similarly, the current results suggest that job satisfaction provides a buffering effect for the perception of work stress. This study did not show a direct effect of job satisfaction on intention to continue employment, but it was a precedent factor of both job stress and of organizational commitment.

Another conceptualization of the role of job satisfaction was presented by Takagi, ${ }^{[9]}$ who explained it as follows: job satisfaction is easily affected by daily events, but organizational commitment is an overall feeling in response to the whole organization. As such, this feeling is formed slowly, and tends to be stable. Therefore, we think that it is difficult to promote intention to continue employment only through the satisfaction felt when one successfully performs his/her duties, as this is a personal feeling that is not easy to change. However, it is first necessary to ensure that work satisfaction is stable, as a desire to grow within one's profession does not occur if stability in one's personal life is not obtained. ${ }^{[12]}$
It should be noted that autonomy and nurse group cohesiveness did not appear in this model. A possible reason for this may be that, in Japanese tertiary care facilities, nurses are legally required to entrust decisions regarding nursing care to a physician. Therefore, this may lower the autonomy of nurses.

Regarding cohesiveness, strong bonds between coworkers do not necessarily lead to the intention to continue employment at a particular institution. Conversely, if an individual forms a strong bond with his/her coworkers, this bond may continue past employment, as can be seen in many retired employees. Unfortunately, no studies have provided evidence that productivity and/or efficiency increases with increased work group cohesion. ${ }^{[9]}$ However, it shows the character of the emergency care institutions, which treat many emergency patients and serious cases, that the collaborative relationships between nurses and physicians are the basis of the model.

A previous study reported that, when the collaborative relationships between nurses and physicians were good in the ICU, patient outcomes improved. ${ }^{[20]}$ Similarly, it may be said that good collaborative relationships between nurses and physicians can also be associated with the provision of improved patient care in tertiary emergency facilities.

\subsection{Strategies to promote intention to continue employ- ment}

It is essential to do whatever is necessary to retain nurses in critical care facilities, as shortages in these areas can have negative impacts on patient outcomes. Therefore, the results of the current study suggest that the collaboration between nurses and physicians should be promoted. Additionally, institutions should strive to enhance nurses' attachment to the organization, improve job satisfaction, and reduce work stress. Concretely, it is necessary to support a work environment where a nurse and a physician can recognize each other as team members, both working towards the same goal. Additionally, it is necessary to set a salary that is commensurate with the work being performed, coordinate a schedule of time off to assist personal life stability, and maintain an environment that can facilitate participation in decision making, according to individual ability. Furthermore, enhancing knowledge, building an education system that boosts the acquisition of technical skills, and facilitating a good relationship with a senior mentor can aid in reducing work stress. $^{[21]}$

\section{Limitations}

Some limitations of this study should be considered. First, the current model explained $20 \%$ of the variance in intention to continue working in an organization. However, it is impor- 
tant to note that $80 \%$ of the variance remained unexplained. We conclude that there are unmeasured and potentially unknown, factors that may influence intention to continue employment in nurses. Further research is needed to explore other factors of intention to stay, and to test a revised model, based upon the results of the present study.

\section{ACKNOWLEDGeMENTS}

We thank the nurses who participated in this study, and the developers of each measurement tool, who granted us permission to use them in the present study.

\section{CONFLICTS OF INTEREST Disclosure}

The authors declares that there is no conflict of interest.

\section{REFERENCES}

[1] Nichols GA. Job satisfaction and nurses' intentions to remain with or to leave an organization. Nurs Res. 1971; 20: 218 228. PMid:5212054 https://doi.org/10.1097/00006199-1 97105000-00006

[2] Hinshaw AD, et al. Innovative retention strategies for nursing staff. J Nurs Admin. 1987; 17: 8-16. PMid:3647116 https://doi.org/ 10.1097/00005110-198706000-00003

[3] Prestholdt PH, Irving ML, Mathews RC. Predicting staff nurse turnover. Nurs Outlook. 1988; 36: 145-147. PMid:3368350

[4] Cavanagh SJ. Nursing turnover: Literature review and methodological critique. J Adv Nurs. 1989; 14: 587-596. PMid:2671085 https://doi.org/10.1111/j.1365-2648.1989.tb01595.x

[5] Boyle DK, Bott MJ, Hansen HE, et al. Managers' leadership and critical care nurses' intent to stay. Am J Crit Care. 1999; 8(6): 361-371. PMid:10553177

[6] Shader K, Broome M, et al. Factors influencing satisfaction and anticipated turnover for nurses in an academic medical center. J Adv Nurs. 2001; 31: 210-216. https ://doi .org/10.1097/00005110-200 104000-00010

[7] Tourangeau AE, Cranley LA. Nursing intention to remain employed: Understanding and strengthening determinants. J Adv Nurs. 2006; 55: 497-509. PMid:16866845 https ://doi.org/10.1111/j.13 $65-2648.2006 .03934 . \mathrm{x}$

[8] Zangaro GA, Soeken KL. A meta-analysis of studies of nurses' job satisfaction. Res Nurs Health. 2007; 30: 445-58. PMid:17654483 https://doi.org/10.1002/nur. 20202

[9] Takagi H. Psychological side of the organization. Hakuroh Publishing, Tokyo. 2003. [in Japanese]

[10] Ueno K, Nishikawa H. Characteristic of attributes of psychiatric nurses and psychiatric hospitals that influence organizational commitment. Jpn Acad Psych Ment Health Nurs. 2005; 14: 1-10. [in Japanese]
[11] Tounton RL, Boyle DK, et al. Manager leadership and retention of hospital staff nurses. West J Nurs Res. 1997; 19: 205 226. PMid:9078856 https : //doi .org/10.1177/019394599701 900206

[12] Shigiki Y. Validity and reliability of the Japanese McCloskey and Mueller Satisfaction Scale (JMMSS). Bull Tokyo Metro Coll Allied Med Sci. 1997; 10: 123-128. [in Japanese]

[13] Nishibori Y, Moroi K. Burnout and interpersonal environment among nurses. Nurs Res. 2000; 33: 53-65. [in Japanese]

[14] Yamase H, Hasegawa K. Psychological study on stress of the emergency nurse (Part I). Emerg Nurs. 1994; 7: 66-71. [in Japanese]

[15] Yamase H, Hasegawa K. Psychological study on stress of the emergency nurse (Part II). Emerg Nurs. 1994; 7: 71-79. [in Japanese]

[16] Koyano Y. Analysis of related factors in autonomy among professional nurses in acute care hospitals. Bull St Luke Inter Uni. 2001; 27: 1-9. [in Japanese]

[17] Honda K. Influence factors relate to Nurse Intention to remain Employed in Tertiary Emergency Medical Facilities. 2011. [Doctoral dissertation]

[18] Nanba N, Yajima Y, et al. The relationship between job and organizational characteristics, organizational commitment, and intention to leave organization among Japanese nurses. J Jpn Acad Health Sci. 2009; 12: 16-24. [in Japanese]

[19] Shimazu M. Job satisfaction and Psychologic stress: Organization and personal stress management. Kazamashobou Publishing Co., Ltd, Tokyo. 2007.

[20] Baggs JG, Schmitt MH, et al. Association between nurse-physician collaboration and patient outcome in three intensive care units. Crit Care Med. 1999; 27: 1991-1998. PMid:10507630 https: //doi.org/10.1097/00003246-199909000-00045

[21] McGilton KS, Hall LM, et al. Supervisory support, job stress, and job satisfaction among long-term care nursing staff. J Nurs Adm. 2007; 37: 366-72. https://doi .org/10.1097/01. NNA.0000285115. $60689.4 \mathrm{~b}$ 